\section{ANKLE-JOINT FRACTURES.}

To the Editor of THE TANCET.

SIR,-Sir W. Arbuthnot Lane, in his instructive paper on Abduction Fractures of the Ankle-Joint in THE LANCET of Oct. 1st, has done well to draw the attention of surgeons both to the mechanics of the injury, as well as to the permanent lameness which only too frequently is left behind. These unfortunate results are, in his opinion, largely due to the tendency of lumping together under the generic name of "Pott's" all fractures round the ankle-joint, without sufficient consideration of the lines of force which caused them. Cases of lameness and disability caused by these fractures come frequently to my notice, and I have been struck by the apparent difficulty surgeons have in obtaining perfect soundness.

Take, for instance, the first degree of this condition : many a time does it come under observation as being a sprained ankle which is proving slow in recovery. This diagnosis is often due to the presence of adhesions, more likely to occur when there has been a fracture than when a simple sprain has been sustained. In dealing with cases of sprained ankle where no obvious bone lesion is present, the question as to whether the ankle turned outwards or inwards at the time of accident is of importance, since the first degree of fracture only occurs where there has been an abduction of the foot. A radiograph is advisable, more as a guide to prognosis than diagnosis, since treatment where displacement is negligible is practically the same as in a sprain, but the period of disability is prolonged.

In the second degree of fracture, though accurate splinting can bring about good results, yet it must be acknowledged that permanent lameness is far from uncommion; so much so that at one time in our police force the fact that a man had sustained a "Pott's" fracture was considered a bar to his further employment.

The third degree of this fracture would appear to offer enormous difficulty to a satisfactory result under manipulation, and quite recently, I have seen a case of this kind, where the resultant distortion and lameness was pitiable. The accident occurred early in February of this year, whilst the patient - a man of about $40-$ was walking through a Borneo jungle. The medical man tried to get reduction under anasthesia, even tually putting the limb up in plaster-of-Paris. Three weeks later the patient was able to be removed to Jesselton, where a radiograph showed the position of the bones to be precisely as in Fig. 3 of Sir Arbuthnot Lane's paper. Another attempt was made at reduction without result. The patient became dangerously ill from shock, and after some weeks was sent to England with a note stating that he had sustained a fracture-dislocation of the right ankle. On examination the leg was found to be thin and emaciated, with limited flexion of the foot, intense muscular wastage of the thigh with contraction of the knee ; the upper end of the tibia formed a projection over the instep, whilst the os calcis formed a corresponding curve behind. A further radiograph showed the position of the bones as before, but the formation of callus and the general condition of the joint made operative interference inadrisable. Treatment by massage and graduated exercises is now making the best of a bad job. The patient was inclined to find fault with the attention he had received in Borneo, but the result, although undoubtedly disastrous, was no worse than is seen in cases where greater facilities for treatment have been available.

Considering the doubtful results so often obtained by the present method of setting and splinting these ankle-joint fractures, I am convinced that reduction by the operation procedure described by Sir Arbuthnot Lane holds out an almost certain prospect of soundness, since an almost perfect apposition can be obtained by a knowledge of the mechanics involved in the causation of the fracture.

$$
\text { I am, Sir, yours faithfully, }
$$

Seymour-street, W., Oct. 15th, 1921. FRANK RoMER.
TEACHING "DEAF-MUTES" TO HEAR.

\section{To the Editor of THE LANCET.}

SIR,- - In the annotation in your issue of Oct. 8th on the late Prof. Urbantschitsch's paper on the use of acoustic exercises in the education of deaf-mutes, you do not refer to the work on similar lines which has been independently carried out in England, and to which reference was made in my Croonian Lectures published in your columns about a year ago. At the Birmingham meeting of the Association of British Physicians in April of this year I showed seven "deaf-mutes," ranging in age from 5 to 32 , who were being taught to hear. All of them had been regarded as absolutely deaf both by their parents and by well-known aural surgeons who had seen them with me, but as they all showed normal vestibular reactions, I thought their deafness was probably functional. After periods varying from a year and a half in one case to between two and six months in most of the others considerable improvement had occurred. Each of the patients was now able to hear a large variety of sounds; one of them could hear the clicking of coins at a distance of 30 feet. Each could recognise and understand ai considerable number of words, and four of them were able to carry on a conversation, when sentences were spoken slowly and in a loud voice close to their ears. Two of the children are having all their ordinary lessons by ear instead of by lip-reading.

Improvement has so far been continuous, though. slow, and I think that there is a good prospect that the more intelligent among them will eventually learn to hear sufficiently well to enable them to carry on ordinary conversations.

I am, Sir, yours faithfully,

ARTHUR F. HURST.

New Lodge Clinic, Windsor Forest, Oct. 11th, 1921.

\section{OCCUPATIONAL THERAPY IN HEART DISEASE.}

To the Editor of THE LANCE'.

Sir,-When a diagnosis of heart disease has been made in a child the questions arise of the scope and direction of the child's education, and of the extent to which games may safely be indulged in. For the adult with permanent cardiac disability advice is needed with regard to suitable occupation; the value to the individual of every year of even a restricted working capacity is apparent, not only in the light of the achievements of the phthisical Keats and R. L. Stevenson, the blind Milton and the epileptic Napoleon, but also with regard to recent post-war experience of occupational therapy, which enables blind and otherwise crippled men to find a place in industry, and thereby enjoy a measure of contentment. That a great deal can be done in this direction is shown in a recent contribution to the Modern Hospital, January, 1921, by Dr. F. L. Brush, medical director of the Burke Foundation, White Plains, N.Y., in a paper mainly based upon experience of over 2500 cases of heart disease, of which more than 2000 had valvular deficiencies.

The plan followed by Dr. Brush may be briefly outlined. The first thing is to undo the effect of wrong advice " of physicians, relatives, employers, teachers," replacing "don'ts and can'ts by do's and can's." The patient recovering from acute disablement is given light hand-work in bed or chair and exercised up to fitness for transfer to a convalescent home, where he goes through four to nine weeks of gymnastic exercises, increasingly active physical play and grade walking, diversional occupation, and short hours of actual work about the institution, often on a handicapped wage. Gradual advance to full-time employment in the institution with medical oversight leads later on to the former job or to another expertly chosen by the "follow-up " agency. The author indicates the various occupations for which his patients have become fitted, such as gardening and carpentry for men and needlework for women. Dr. Brush advises the continuance 